\title{
As tradições da Faculdade de São Paulo (*)
}

\author{
A. de Sampaio Doria \\ "Debaixo destes tectos duas evidências ha \\ que nos consolam, nos desmaginam e chegam \\ a desconvencer-nos da morte: a continuidade \\ da tradição e a continuidade da justiça". RUY
}

Estas palavras do Mestre sem igual bem é que sejam lidas, todos os dias, nesta casa, pela mocidade que a freqüenta.

Não apenas lidas. Lidas e meditadas; meditadas e praticadas. Jamais trair as conviç̧ões que nos animem. Nada corrói tanto o feitio moral ao homem, como o hábito de não andar êle de harmonia com os princípios que adote. A dupla-face que traz a boca enfatuada de preceitos, e o coração vasio de sinceridade, corrompe com doçura a juventude inexperta, que a contempla. Vai-se-lhe convertendo em balda o artifício de que repetir é pensar, e salvar as aparências é proceder bem.

RuY, cujo caráter superava em grandeza moral o gênio e o saber que a todos assombrava, não evocou as tradições desta Faculdade, como simples figura de retórica, para enlêvo dos que se fascinavam com sua eloqüência. Vibra, em suas palavras, advertência profunda, cujos ecos, como toques de clarins, que desaparecem ao longe, ainda ressoam a nossos ouvidos atentos.

(") Discurso pronunciado, a 14 de novembro de 1944, em nome da Faculdade de Direito da Universidade de São Paulo, no ato da inauguração da placa comemorativa de Rui Barbosa, oferecida à Faculdade pela Associação dos seus Antigos Alunos. 
Certo, não é, na geração dos estudantes de hoje, que, acaso, tenha a continuidade das tradições, e a continuidade da justiça, que ele exaltou, sof rido eclipse ou deslustre. A geração dos moços a quem falo, acordando para a vida na mais sinistra fase da humanidade, se, alguma vez, deslumbrada com a poeira de ouro de frases bem soantes, vacilou, desmentindo-se a si mesma, soube, logo, a tempo, desvendar os olhos, para não confundir nem a Pátria, nem Deus, nem a Familia, com a ambição dos déspotas, a hipocrisia de seus intuitos, e a crueldade de seus processos.

E que o espirito desta casa, a voz de cujos professores, ainda os de outrora, lhe repercute rediviva em cada canto, é de cultura, liberdade e justiça. E estes ideais, os moços não os renegam, não os traem, a preço de nenhuma sedução, nem por temor a nenhum perigo.

Não nos enganemos, porém, com palavras.

A liberdade, de que estão impregnados os ares desta casa, não é a mesma cousa que atividade indiscriminada dos homens. Não consiste no poder de fazer cada qual o que deseje. Mas o que deve. E o que deve, como parcela da sociedade, a que pertença, é o que fôr compativel com a vida coletiva, que ela proporcione. A liberdade que vos louvo, é o poder, inerente à criatura humana, de fazer, ou deixar de fazer tudo o que não desagregue a sociedade, nem the embarace o progresso. Nesses termos, por mais que vos pareça de arrepio com as ideas correntes, nem mesmo o direito a restringe. $\mathrm{O}$ a que a lei ou o direito põe limites, é à atividade indistinta do indivíduo. Mas atividade é gênero, de que liberdade é espécie. A outra espécie é o abuso, cujos horizontes podem dilatar-se até ao crime.

$\mathrm{E}$ esta liberdade, por amor da qual não cessam as lutas contra os escravocratas, é a suprema tradição de justiça da Faculdade de São Paulo, a evidência de cuja continuidade Ruy assinalou, nas palavras memoráveis, que a Associação dos Antigos Alunos, em tão feliz inspiração, insculpiu em bronze, para reavivar, a cada geração que por aqui passe, a memória da lição imperecivel. A justiça mais não é que 
uma síntese da liberdade e da igualdade. E a liberdade é tão compreensiva que sumaría, não só quatro, mas, pelo menos, seis liberdades: a de locomoção, a de pensamento, a de crença, a política, a de reunião e associação, e a de trabalho.

Onde quer que a liberdade física se ache exposta a prisões arbitrárias, e não se tenha, para restaurá-la, de quem obter hàbeas-corpus, aí a justiça desapareceu. $\mathrm{E}$ uma das gloriosas tradições desta casa perdeu, lá fora, a aplicação, a pesar da continuidade que, agora, vos é lembrada.

Onde quer que se não possa publicar, sem ofensa a ninguém, na imprensa, no rádio, na tribuna, ou na praça pública, o que se pense seja sobre o que fôr; onde quer que se não abra, sôbre os problemas sociais, debate irrestritn, com garantia judiciária contra abusos de poder; onde quer, em suma, que subsista, na paz, censura à imprensa, aí a justiça foi sacrificada. E mais uma das nobres tradições desta casa perdeu, lá fora, o prestígio, mau grado da continuidade que, agora, vos é louvada.

Onde quer que não possa o homem propagar sua fé, e celebrar em público seu culto, aí a justiça pereceu. E outra das grandes tradições desta casa perdeu, lá fora, a eficiência, sem quebra da conținuidade que, agora, vos é recomendada.

Onde quer que, por amor da eficiência coletiva, se sacrifiquem as iniciativas individuais, sob economias dirigidas; onde quer que, no trabalho sob salário, monopolize o Estado os instrumentos de produção; onde quer que se prive aos particulares fazerem o que lhes apraza, do que produzam e é seu, aí a justiça foi mal-ferida. E mais outra das honrosas tradições desta casa perdeu, lá fora, o valor, em que pese à continuidade que, agora, vos é exaltada.

Onde quer que, para seu destino, não eleja o povo os seus dirigentes, nem os responsabilize nas urnas, aí a justiça foi repudiada. E ainda outra das altas tradições desta casa perdeu, lá fora, a graça da vida, a despeito da continuidade que, agora, vos é gabada. 
Onde quer que não possa o homem associar-se a outros homens, em prol dos ideais que os inflamem; e, maiormente, onde forem capitulados por nocivos à pátria os partidos com que a opinião pública se organize, aí a justiça foi traída. E outra mais das magníficas tradições desta casa perdeu, lá fora, o préstimo, não obstante à continuidade que, agora, vos é celebrada.

Começais dest'arte, meus jovens amigos, a devassar o espírito profundo das palavras de Ruy, proferidas, entre nós, há mais de três décadas, quando pelejava, como titâ, pela ordem civil, na maior campanha política, que já se realizou no país.

Ruy condicionava, então, a realidade da justiça, na sociedade, à realidade do voto, com que ela estruture o poder, sob que viva. Apostolava, numa equação estável entre as suas convicções, e seu procedimento, o princípio de que a direção em tudo, neste mundo, pertence, por natureza, aos que lhe suportem as conseqüências. E, dai, a verdade ineqüívoca de que a legitimidade do poder é o assentimento dos governados, não apeṇas presumido, não apenas tácito como túmulos, mas expresso em eleições periódicas, a que preceda, a coberto de ameaças, o debafe público, sem segredos de Estado, agitado e clamoroso embora, mas tudo por amor da verdade, como, ainda agora, na grande República do Norte.

Fora disto, tudo é opressão. E, com a opressão, todos os ideais de cultura, liberdade e justiça, com que acaso vos embalem, não passam de palavras ociosas, embustes, ou enganos.

Tão imperativos à humanidade são os princípios de justiça, cuja continuidade nas tradições desta casa, Rux pôs em relêvo, que, no anseio de constituição do mundo d'amanhã, anda no ar, como condição da paz universal, a segurança internacional da democracia e dos direitos do homem.

Quando as duas grandes potências da Europa e da América prometeram, no item $3 .^{\circ}$ da Carta do Atlântico, respei- 
tar a todos os povos o direito de escolherem o sistema de govêrno sob que desejem viver, claro está que não embandeiravam em princípio de direito internacional respeito supersticioso a qualquer govêrno que cada povo tenha. Pois, não foi para eliminar da face da terra o fascismo, com que a Italia se arruinou, e o nazismo, com que a Alemanha desgraça o mundo, que as Nações Unidas, inclusive o Brasil, perdem, neste momento, nos campos de batalha, a flor de sua juventude heróica? O que a Carta do Atlântico alçou em ideal nas relações entre os povos, foi o respeito internacional à livre determinação política de cada povo. E quem baralha eleição política pelo povo, com imposição política ao povo? Eleger o povo o govêrno que deseje, não é evidentemente ter o povo govêrno que não eleja.

Grande sabedoria política, e não menos tino diplomático, de que se vai ter a prova, na próxima organização da paz, estão em não permitir ingresso à Sociedade das Nações, que se projeta, aos povos sem voz, nem voto para seu próprio destino. A nação que não se respeite a si mesma, não respeitando a dignidade aos que a formam, que autoridade moral poderia ter, para esperar que a respeitem?

Nada mais legítimo, mais realista e mais sensato, do. que exigir o Superestado das Nações, no pórtico, á entrada, aos que o vão constituir, o compromisso de viverem sob democracia, e de garantirem liberdade aos indivíduos, a cujos destinos presidam. A emancipação do homem, sem distinção de côr, religião, ou riqueza, é, para o convívio das nações, a profilaxia pela paz: O govêrno em cujos conselhos impere a opinião pública, não tomará jamais iniciativa de deflagrar, hoje mais do que nunca, conflitos armados, para conquista de povos. Sendo fatal ao povo pagar, com a vida e os bens, o custo das guerras que trave, não tem êle nem interêsse, nem ânimo, para as desfechar, nem mesmo para as provocar. Os ditadores, porém, até para manter-se no posto que desfrutem, estão, sempre, a engendrar qüerelas, em que só prevalecem as bocas de fogo. 
A preliminar, pois, para o êxito de um Superestado universal, é não se constituir êle senão de Estados, onde o regime de govêrno seja democrático, e haja garantias absolutas aos direitos do homem.

Com o advento deste Superestado, surgirá, pela primeira vez, no mundo, uma soberania internacional. Esta soberania será o poder supremo, nas mãos da comunidade das nações, para manter a paz universal, fazendo vingar o direito nas relações externas de umas com as outras.

Hoje, o que, nesse terreno, cada Estado frui, é a independência de ação no mundo internacional. Esta independência, a que se costuma denominar, com impropriedade, soberania externa, é a situação, peculiar a cada Estado, de não depender, nas relações com os demais, senão de si mesmo. Para dirimir conflitos de uns com outros, se não der certo a diplomacia que usem, ou falhar a arbitragem a que recorram, o recurso fatal é a guerra, onde, com a voz sem réplica dos canhões, o que, em verdade, decide, é o punho do mais forte e mais temerário.

Com a gênese, porém, de um Superestado de Nações, cada Estado que dele compartilhe, abre mão de sua independência de ação nas relações com os outros, para organizar, com a soberania internacional, a segurança de todos.

Não obstante, nunca foram tão necessários aos povos cautela e bom senso. A paz universal é o supremo ideal de todos. Na troca, porém, da independência de ação, pela segurança coletiva, não haverá, por desventura, armadilha à soberania de cada Estado associado?

Sim, se o Superestado em perspectiva, sob pretexto de manter a paz entre as nações associadas, instituir privilégios de umas sôbre as outras, e intervier de qualquer forma nos negócios internos de cada uma.

Não, se o Superestado em projeto fôr cunhado em moldes de justiça e bom senso.

De justiça pela adoção, desde logo, do princípio da igualdade jurídica das nações, grandes e pequenas, tal como 
o reivindicou o Brasil, na conferência de Haia em 1907, pela voz de seu excelso embaixador, o estadista incomparável da liberdade entre nós: Ruy Barbosa.

De bom senso, pela diplomacia de não terem as leis do Superestado das Nações valor nenhum em cada país, senão depois de aprovadas soberanamente pelos governos respectivos.

Compreende-se que os Estados, sobre cujos ombros pesem maiores encargos, para manter a paz, exerçam votos mais decisivos nas providências que a tornem efetiva. E justo o princípio da proporcionalidade entre os que correm mais riscos em bens e vidas, e os votos para as decisões de que decorram tais riscos. E que semelhantemente ocorre nas sociedades anônimas, em cujas assembléias dispõe de mais votos quem tem nelas mais a perder, sem menoscabo à igualdade jurídica entre as pessoas de seus acionistas.

O acêrto, a firmeza e a prudência, na adoção desta proporcionalidade, serão, talvez, a pedra de toque para o reino do espirito entre os homens.

Dir-se-á que as leis do Superestado, sobretudo quando se trate de garantir a democracia e os direitos do homem, ou transpõem obrigatòriamente as fronteiras de cada Estado, ou não valem nada. Transpondo-as, o Superestado subtrai à nação em cujo território vão imperar, a supremacia de seu poder político, dobrando-lhe a finados a soberania. Era poder supremo e incontrastável, e passa a ser contrasteado e subordinado, como o dos Estados norte-americanos, com a fundação, há mais de século e meio, da União soberana, que os vai levando, nestes dias memoráveis, à suprema direção do mundo contra as guerras.

Tenha-se, porém, em conta, antes do mais, que o fim da soberania de cada Estado não é a escravização do homem. $\mathbf{E}$, pois, quando um povo soberano subscreve a fiança internacional da democracia, o que exercendo está, é, em verdade, a própria soberania. Onde, então, ofensa ao que, na realidade, a consagra? Não se compreende que anule a soberania o ato com que ela vede, até a si mesma, o poder 
de a destruir. 0 propósito de respeitar direito alheio nảo. amesquinha a quem o ponha por obra. A lei que comine pena a criminosos em sociedade policiada, não é ameaça aos homens de bem, senão garantia de seus direitos contra a turbulência dos maus, e o desatino dos loucos.

Tal como quando as nações soberanas se empenham em respeitar e fazer respeitar, entre si, a democracia e os direitos do homem.

As questões com que podem desavir-se os Estados, componentes da Sociedade das Nações, nada obsta a que sejam resolvidas, preliminarmente, por acordos diplomáticos, que promovam, ou laudos arbitrais, que prefiram, como entre quaisquer pessoas em direito privado.

Mas, se em vez da solução diplomática, ou por arbitragem, for um dos componentes da Sociedade das Nações condenado a cumprir obrigações, em favor de Estado com que contenda? Não se teria, ao menos nesta condenação, envolta em crepe a majestade da soberania onipotente?

Aqui, de duas, uma. Ou o Estado vencido se submete espontâneamente às determinações do Superestado a cujo é, ou se rebela.

Na primeira hipótese, sua soberania não está em choque. A submissão espontânea à sentença em que perca a lide, não o pode desmerecer, como não afronta o indivíduo cumprir, nas relações comuns, sentença em pleito que perdeu. Se o vencido fôr, então, grande potência, sua obediência, podendo pelas armas rebelar-se, é exemplo de finura diplomática, e da mais intemerata nobreza. Se o vencido fôr país desarmado, sua conformidade com a sentença é respeito ao direito apurado pelos tribunais, e, pois, nada que o deminua.

Na segunda hipótese, a do Estado vencido, que não se submete, o caso muda de figura. Trata-se de perjúrio, de felonia, de perfídia. O povo que, em nome de uma soberania exaltada, traia seus compromissos solenes, além de se desrespeitar a si mesmo, deblatera. 
Deblatera, porque, nas relações, para além das fronteiras, de Nação a Nação, nunca pode estar em jôgo a soberania de cada uma, cujo âmbito de ação não vai além de seu território. Nas relações para além das fronteiras, o que há, na dosorganização caótica do mundo de hoje, é a independência arbitrária de cada nação. E, na associação política, que organizem, para o mundo d'amanhã, o que haverá, é a soberania internacional, de que será titular a comunidade mesma dos Estados, e não cada Estado em particular.

Se, contudo, por falsa concepção do alcance da soberania de um povo, ainda se houver, na formação de um Superestado de Nações, por decaida a soberania de cada associado; se os melindres ultranacionalistas confundirem a independência de ação de Estado a Estado com a soberania de cada um, então o único recurso, para atender à metafísica dêstes absolutistas, ou lhes acalmar os melindres à flor da pele, é ressalvar a cada componente da Sociedade das Nações o direito de separação. Voltaria o Estado desligado, em seu desdém pela segurança coletiva, à independência de ação internacional, quase sempre à mercê da benevolência dos mais fortes.

Vêde até onde vai o pensamento de Ruy sobre as tradiçõs de justiça da Faculdade de São Paulo. São tradições do direito acima das paixões, dos regimes e dos povos.

Se, outrora, os ideais que the iluminavam as cátedras, inspiraram ao país a emancipação dos escravos, e a proclamação da República, hoje estes mesmos ideais, porque não hão de pelejar, com o poder que possam, pela segurança internacional dos direitos do homem, sem desdoiro à magestade soberana de cada nação?

Liberdade sem garantia, toda gente sabe, é praticamente um não-ser. Como simples outorga da sociedade ao homem, ou concessão revogável do Estado ao indivíduo, só pode satisfazer aos que nasceram, para ser mandados. A liberdade ou tem existência própria, ou nada é. Está na alma do homem, inerradicável, como a inteligência e a vontade. Para que seja garantida em toda sua plenitude, é que os 
homens convertem a força social em autoridade. Daí, a ordem pública, sem a qual não há liberdade efetiva. Liberdade sem garantia, é, na prática, um não-ser, como as ficções com que se excitem a imaginação às crianças.

O estribilho, descorado e rouco, de ser o liberalismo cousa morta, no mundo que ressurgirá desta guerra, é canto de sereia na preparação, no advento, ou na conservação das ditaduras. Contra o liberalismo, arvoram em flâmula a socialização do direito. Mas aqui, até a frase já é distituída de senso lógico. $O$ direito ou é social, ou não é direito. Fora das relações humanas, não ha fenômeno jurídico. Logo socializar o direito o mesmo é que socializar o social, e, pois, malbarateio de palavras.

Para reparação das injustiças habituais, e lograr que cada um receba o que é seu, foi, nestes últimos tempos, tambem mal cunhada a frase democracia social, tão do sabor de tantos. Não ilumina, porém, o termo nem lógica, nem conteúdo próprio. É frase sem sentido que se salve.

O valor do adjetivo é especificar o substantivo, com lhe adensar a conotação. Mas se social é gênero, de que democracia é espécie, como há de o gênero, com a idea genérica, especificar qualquer de suas espécies, se a idéa genérica, que o define, já se inclui em cada uma das espécies, em que se divida? o que caracteriza as espécies, é o que se acrescente à idéa gênérica, que elas já trazem em si. Como, então, com a idéa genérica, expressa sob a forma adjetiva, aditar qualquer cousa à mesma idéa já constituida em substantivo? Democracia social, sendo social o gênero, e democracia a espécie, é, pois, frase indefensável perante o senso comum.

Não obstante, ela se universalizou, como socialização do direito, para pleitear um ideal, que, sob o rótulo de novidade, nada inova. O que a democracia social de justo pleiteia, é a proteção legal do fraco que renuncie por necessidade, em face do forte que oprima por ganância, do empregado que se submeta sem remédio, ao capitalista que explore 
por ambição, do pobre que ajoelhe em lágrimas, junto ao rico que tripudie com luxos.

Mas este propósito de justiça, que a democracia social acena em novidade, é, numa compreensão mais exata da liberdade, o ideal mesmo, em corpo e espírito, da democracia liberal (e aqui a frase já tem senso lógico). Nem se compreende democracia sensata, que não seja, em consequência, liberal. Certo, democracia é uma cousa, e liberalismo outra. Mas quem fôr democrático, só por anomalia deixaria de ser liberal, como quem se arda em sêde, só por demência deixaria de dessedentar-se em fonte pura, que lhe esteja ao pé.

Todo o cuidado é pouco, senhores, com a eqüivocidade dos termos! E a grande arma dos demagogos, que tudo prometem, e nada cumprem.

A lição de Ruy não é, porém, ludíbrio aos moços. A Faculdade de São Paulo, cujas tradições a palavra do Mestre vos trará, neste bronze, em perpétua memória, não creio, sejam quais forem as provações que a esperem, esmoreça jamais em sua doutrinação desinteressada pela liberdade e pela justiça.

Se, por desgraça inenarrável, ainda desta vez viesse a falhar a consolidação da paz, e a segurança do direito no mundo, a Faculdade de São Paulo não mudaria de credo. Continuaria a doutrinar aos moços a justiça, sem a qual não há civilização, e a pregar a democracia, sem a qual não há liberdade. 